\title{
PROUST VISITA OS ANTIGOS: PROJETO CRIADOR E REPRODUÇÃO SOCIAL NA FRANÇADA TERCEIRA REPÚBLICA
}

\author{
Proust delves into the Ancients: creative project and \\ social reproduction in the French Third Republic
}

\author{
Rafael Faraco Benthien*
}

\begin{abstract}
RESUMO
O propósito do presente artigo é refletir acerca do lugar social reservado aos clássicos greco-latinos na França de inícios do século XX, justo quando eles se encontravam no centro de uma rápida e controversa reforma do sistema de ensino deste país. Para tanto, privilegia-se aqui a última fase da produção literária e crítica de Marcel Proust (em especial, Contre Sainte-Beuve e À la Recherche du Temps Perdu).

Palavras-chave: Proust; clássicos; França (Terceira República).
\end{abstract}

\begin{abstract}
This article assesses the social place of greek and latin classics in early twentieth France, when these subjetcs were at the core of a fast and controversial educational reform. It will be emphasized the last phase of Marcel Proust's literary and critic production (specially Contre Sainte-Beuve and À la Recherche du Temps Perdu).

Key-words: Proust; classics; France (Third Republic).

* Doutorando em História Social na Universidade de São Paulo e bolsista Fapesp. Tal artigo apresenta resultados parciais de meu doutorado em andamento, no qual discuto tanto o impacto da institucionalização da sociologia nos estudos clássicos franceses, quanto o lugar dos clássicos grecolatinos na nova ciência (em especial, entre 1887-1920). Agradeço aqui aos interlocutores que, durante as apresentações de versões preliminares deste texto, tanto no XXIX Simpósio Nacional de História, quanto no I Simpósio Antigos e Modernos da Universidade Federal do Paraná, permitiram que eu aprimorasse o trabalho com suas generosas considerações. Sou especialmente grato a Rodrigo Turin por sua atenta leitura, bem como às revisões de Patrícia Faraco Benthien e de Leonardo Marques.
\end{abstract}




\section{Introdução}

No presente estudo, trato do lugar social reservado aos clássicos greco-latinos na França da Terceira República (1870-1940), justo quando eles se encontravam no centro de uma rápida e controversa transformação de todo o sistema educacional desse país. Para tanto, privilegio aqui os derradeiros anos da produção literária e crítica de Marcel Proust - ou seja, o período iniciado em 1909 com a redação do romance À la Recherche du Temps Perdu, então ainda integrado em Contre Sainte-Beuve. Na primeira parte do artigo, proporei uma leitura do projeto estético proustiano para, em seguida, situar nele as referências aos antigos, seja como eventual suporte deste mesmo projeto (via resgate ou crítica de algum cânone), seja como simples conjunto de dados mobilizado no enredo de sua obra. Antes, porém, cabe apontar as razões pelas quais Proust é particularmente estratégico para iluminar algo da situação dos clássicos na França.

Sobre isso, antes de mais nada, deve-se considerar certas especificidades das políticas educacionais da Terceira República. Em tal período, os ensinos médio e superior não só foram unificados, como também reordenados a partir da criação de centros de produção e difusão de conhecimento científico original. Tudo girava em torno da substituição de um modelo de ensino por outro, considerado mais adequado a uma nação dita progressista e republicana ${ }^{1}$. Em linhas gerais, o modelo a ser superado era ainda o jesuítico, um legado do Antigo Regime devidamente reatualizado pelas reformas napoleônicas. Tal modelo, quanto ao ensino médio, era formado por liceus encarregados de oferecer um currículo quase que exclusivamente clássico, ou seja, centrado em exercícios de retórica/estilo ligados às línguas e literaturas francesa, latina e grega. Já no ensino superior, a Universidade tinha a dupla função de formar professores aptos a atuar nos liceus e de fiscalizar sua atuação, relegando assim a produção do conhecimento científico original a instituições desconectadas do sistema educacio-

1 Veja-se, sobre este ponto, RINGER, Fritz. Fields of Knowledge. Cambridge: Cambridge University Press, 1992, p. 196-247, bem como MAYER, Françoise. Histoire de l'Enseignement et de l’Éducation. Paris: Pérrin, 2004, p. 315-579. 
nal, tais como o Institut de France e toda uma série de clubes privados². Em oposição a uma tal tradição, propunha-se então algo inspirado no caso alemão. Com efeito, do outro lado do Reno, desde fins do século XVIII, uma elite letrada de origem burguesa promovia pesquisas metódicas e inovadoras a partir da Universidade, mantendo-se em uma posição central na vida política e cultural do que mais tarde seria a Alemanha ${ }^{3}$.

Ainda que a ciência alemã pressionasse o sistema educacional francês desde antes da Terceira República, a instauração deste novo regime, decorrência direta da derrota militar (e "científica”) para a própria Prússia, acabou acelerando o passo das reformas. Em menos de cinqüenta anos, de 1870 a 1914, o lugar institucional dos clássicos greco-latinos sofreu significativas perdas. No ensino médio, por exemplo, as línguas modernas, a história, a filosofia e as ciências naturais aos poucos ganharam terreno, até que, em 1902, tornou-se possível ingressar na Universidade sem estudar latim ou grego. Já no ensino superior, ciências como a história “metódica”, a sociologia e a história literária deslocaram o foco do aprendizado. Agora, ao invés de imitar formas retóricas, os estudantes eram encorajados a refletir metodicamente sobre o Homem, o de ontem e o de hoje, em tudo o que remete à sua existência social ${ }^{4}$.

Além do caráter institucional e do conteúdo das reformas, outro dado a ser considerado é a mobilização de amplos setores da sociedade que elas suscitaram. E aqui não havia meio-termo: ou se era contra, ou a favor. Entre os simpáticos à causa, pode-se situar os então chamados intelectuais. Forjados em meio ao Affaire Dreyfus, em fins do séc. XIX, tal grupo reunia a nova elite letrada francesa, entusiasta da ciência e da república. Jaurès, Durkheim e Lanson encontram-se em suas fileiras. Do outro lado,

2 Sobre o funcionamento do Liceu e da Universidade na França durante o século XIX, veja-se PROST, Antoine. Regards Historiques sur l'Éducation en France. Paris: Belin, 2007, p. 101-116; 149-152. Já sobre a tradição de ensino dos clássicos no século XVIII, em parte recuperada pelos liceus, cf. GRELL, Chantal. Le dix-huitième siècle et l'antiquité en France (v. 1). Oxford: Alden Press, 1995, p. 1-44.

3 No tocante à constituição histórica e à especificidade da Universidade Alemã, cf. RINGER, Fritz. O declínio dos mandarins alemães. São Paulo: Edusp, 2000.

4 Uma importante síntese das perdas institucionais e da modernização temática dos clássicos na França, centrada na oposição entre religião e estado laico, pode ser encontrada em DABDAB TRABULSI, José Antônio. Religion Grecque et Politique Française au XIXe. siècle. Dionysos et Marianne. Paris: L’Harmattan, 1998. 
batendo de frente com os reformistas, estavam os que se sentiam atacados e/ou desiludidos com as bandeiras republicanas. Tratava-se de um grupo bastante heterogêneo, reunindo velhos monarquistas, novos nacionalistas (como os membros da Action Française) e escritores outrora próximos aos republicanos como, por exemplo, Charles Péguy.

O dado a ser considerado nesta cisão da elite letrada da Terceira República é que ela opõe literatos e cientistas, reatualizando assim o padrão de lutas característico de toda a história pós-revolucionária francesa ${ }^{5}$. De fato, desde a sensibilidade romântica dos primeiros anos do século XIX, forjada por personagens politicamente conservadores como Mme. de Staël e Chateaubriand, a atividade literária se constituiu contra os partidários da ciência e da república (em particular aqueles que, durante a Primeira República, como Cabanis, Volney e os chamados ideólogos, estavam interessados em tratar cientificamente de questões morais e sociais). Da mesma forma, nas décadas de 1890 e 1900, a maioria dos literatos e dos críticos opôsse com violência às reformas. É assim que Barrès, Péguy e Brunetière, mesmo consideradas as diferenças entre eles, foram unânimes em denunciar: o ataque ao "humanismo clássico" (ou seja, ao estudo retórico das línguas grega e latina) estaria minando a boa escrita francesa, colocando em seu lugar conteúdos republicano-científicos acríticos, ou mesmo amorais ${ }^{6}$. Eis então que aqui se impõe a questão: em meio a tais conflitos, onde situar Proust? E mais: como poderia ele dizer algo novo sobre isto?

A grande vantagem da obra do referido escritor para o analista moderno está em sua aparente indiferença ao tema, o qual é abordado apenas en passant e indiretamente, por meio de seus enredos e personagens ${ }^{7}$. Tal atitude, no entanto, aponta para as posições muito peculiares que Proust ocupou na sociedade francesa de então. Há que se considerar aí, em primeiro lugar, uma formação escolar bastante ambígua, tradicional, mas sensível

5 Veja-se a tese sustentada em HEILBRON, Johan. La naissance de la sociologie. Marseille: Agone, 2006, pp. 153-266.

6 Para uma história destes embates durante a Terceira República e sua herança, veja-se COMPAGNON, Antoine. La Troisième République des Lettres. Paris: Seuil, 1989.

7 Os dados biográficos aqui utilizados foram retirados de: TADIE, Jean-Yves. Marcel Proust. Paris: Gallimard, 1996. Consultei também WHITE, Edmund. Marcel Proust. Nova York: Penguin Putnam, 1999. 
à inovação. Assim, no liceu Condorcet dos anos 1880, além do acesso aos clássicos, Proust se sensibilizou com as aulas de Alphonse Darlu, o filósofo neo-kantiano partidário das reformas educacionais e entusiasta das ciências sociais. No ensino superior, na década seguinte, apesar de ter conjugado os cursos nos quais era recrutada a elite de sua época (a tradicional graduação de Direito na Sorbonne e a de Política na nova École Libre de Sciences Politiques), travou também contato com professores universitários ligados às vanguardas científicas (é o caso, por exemplo, do filósofo Victor Brochard, que ele conheceu nos salões de Mme. de Caillavet).

Deve-se ainda notar também uma similar ambigüidade nos investimentos de Proust nos espaços de produção artísticos. A despeito do desejo precoce de se tornar escritor, algo materializado na adesão a inúmeras revistas e salões literários da época, sua atuação no Affaire Dreyfus em consonância com "partido intelectual" o indispôs com importantes pessoas do ramo. O mesmo pode ser dito de seu círculo íntimo e origem sociais: um judeu por parte de mãe que circulava tanto nas esferas aristocrático-burguesas como naquelas de seus empregados - o que tanto lhe valeu a fama de snob quanto ajudou a tornar pública sua homossexualidade. Some-se a isso ainda uma produção artística bastante irregular. Entre 1896, ano da publicação de seu primeiro livro, e 1913, quando lança Du côte de chez Swann, Proust só produz breves artigos e resenhas, além das traduções de Ruskin, o escritor e sociólogo inglês. No mais, vê dois de seus grandes projetos frustrados: os romances Jean Santeuil e Contre Sainte-Beuve. E mesmo quando, ao fim da vida, tem a consagração do prêmio Goncourt, dado à seqüência de Du côte de chez Swann, ela é controversa: o resultado é decidido por um só voto, em meio a duras críticas da obra e denúncias de propinas dadas aos juízes.

Por fim, um terceiro ponto a ser destacado é a relativa independência financeira garantida pela herança familiar. Sua mãe, Jeanne Weil, filha de ricos judeus provinciais engajados no mundo das altas finanças e da política, já possuía um espólio considerável, que o sucesso profissional do marido, Adrien Proust, só fez aumentar. Este, por seu turno, descendente de pequenos comerciantes de Illiers e graduado em Medicina na capital, tornou-se mundialmente conhecido por conceber e ajudar a instalar cordões sanitários na Europa. É assim que, após a morte de seu pai e de sua mãe, respectivamente em 1903 e 1905, o escritor, então na casa dos trinta anos, 
dispunha de um capital econômico significativo, capital este gasto em nome de seus projetos estéticos.

Enfim, o fato é que Proust parece estar em todo e em nenhum lugar. Os handicaps são muitos - descendente de judeus entre nobres, burgueses e populares, asmático, homossexual e dreyfusard -, assim como os trunfos - a herança familiar e a educação polivalente (ao mesmo tempo tradicional e moderna). Mas se essa profusão desnorteia o analista, como notou Benjamin: ela igualmente torna as impressões de Proust sobre sua sociedade um verdadeiro achado ${ }^{8}$. Afinal, inovando diante dos padrões comportamentais e estéticos vigentes na época, ele consegue discutir detalhes de sua sociedade que outros sequer seriam capazes de perceber.

\section{Arte e sociedade em Proust: uma leitura de Un Amour de Swann}

Para problematizar o lugar social dos clássicos greco-latinos na França a partir da obra do derradeiro Proust, é preciso antes compreender algo de seu projeto estético. Por conta disto, discutirei aqui um trecho de $\grave{A}$ la Recherche du Temps Perdu, intitulado Un Amour de Swann, no qual o

8 Em especial, BENJAMIN, Walter. Magia e técnica, arte e política. São Paulo: Brasiliense, 1994, p. 36-49. Interessante notar que Benjamin constrói uma imagem bastante positiva da obra de Proust, na qual localiza uma crítica mordaz ao sistema de reprodução das diferenças (sejam elas econômicas, políticas, ou culturais) da sociedade burguesa (as palavras são minhas). Ainda assim, justamente por Proust ver na arte um meio de transcendência individual, como mostrarei na seqüência do artigo, uma leitura oposta à de Benjamin é também possível. Vale dizer: o artista proustiano critica sim a sociedade à qual pertence, mas não o faz para propor um novo modelo de sociabilidade, e sim para mostrar como ele é superior no interior do modelo já existente. As impressões de Deleuze sobre Proust poderiam ser discutidas em uma direção muito parecida (veja-se DELEUZE, Gilles. Proust e os signos. Rio de Janeiro: Forense Universitária, 2006). Deleuze, afinal, está interessado em estudar todo o mecanismo de transcendência da arte proustiana, que ele curiosamente descobre ser muito próximo ao de sua própria filosofia. Em nenhum momento, porém, o filósofo se questiona sobre os efeitos sociais (e não os "puramente” metafísicos ou intelectuais) desse mecanismo, nem sobre aquilo que o tornou socialmente (e não metafisica ou intelectualmente) possível. Nesse sentido, parodiando Pascal, poder-se-ia dizer que Deleuze privilegia a lógica interna da arte, sem questionar em nenhum momento a arte (ou os efeitos) da lógica social na qual a atividade intelectual, seja ela filosófica ou artística, está inserida. 
narrador apresenta um dos mais importantes heróis do romance, Charles Swann ${ }^{9}$. Tal procedimento, o de uma leitura interna, é apenas justificável na medida em que o trecho escolhido fornece elementos para sua própria análise sócio-histórica. Vale dizer: estão ali representadas as relações sociais com as quais o próprio escritor francês precisou lidar para construir um espaço reservado exclusivamente ao artista, espaço este definido por uma vivência estética, ou seja, um padrão comportamental característico (padrão oposto, por exemplo, ao modus vivendi burguês/aristocrata mundano, ao dos pequenos burgueses provinciais, bem como ao de seus empregados) ${ }^{10}$.

Em Um Amour de Swann, a sociedade de inícios da Terceira República é vislumbrada a partir de dois salões, o dos Verdurin e o dos SaintEuverte, bem como tudo o que os tangencia (os demais salões e o mundo dos empregados). Tais salões são apresentados como modelos opostos de sociabilidade (um, pequeno-burguês-individualista; o outro, aristocráticohierárquico), e concentram toda ação, cadenciada pelas idas e vindas de Charles Swann.

Mas quem é o herói? Ora, desde o início do romance sabe-se que Swann é judeu de origem e atua no mundo das altas finanças, profissão herdada de seu pai. De modos elegantes e parisienses, radicalmente opostos ao dogmatismo da burguesia provincial, ele é também um colecionador e estudioso de arte, filosofia e história (aprecia Pascal, Saint-Simont, Corot, Ver Meer, bem como as vanguardas artísticas de seu tempo). Além disso, outro sinal de distinção, ele freqüenta as melhores companhias mundanas (o Jockey Club, o salão dos Guermantes, entre outros). No trecho aqui selecionado, porém, descobre-se que Swann igualmente circula em outros ambientes, motivado, sobretudo, por conquistas amorosas. E aí, em meio à (ou mesmo apesar da) alta sociedade, encontram-se domésticas, operárias e Mme. de Crecy, ou só Odette, uma demi-mondaine por quem Swann se apaixona e com quem mais tarde se casa e tem uma filha.

Odette, que Swann conhece na saída de um espetáculo teatral, conquista o herói justamente por reunir em si signos estranhos aos espaços

9 PROUST, Marcel. À la Recherche du Temps Perdu. Paris: Gallimard, 1999, p. 157-305.

10 Similar análise foi realizada exemplarmente em BOURDIEU, Pierre. As regras da arte. São Paulo: Cia das Letras, 1996, p. 17-59. 
sociais nos quais ele passa a maior parte do tempo. Ela possui uma história pessoal nebulosa (a qual inclui um estágio em Nice antes de chegar a Paris) e não se destaca exatamente por seus conhecimentos em arte (aprecia músicos menores, como Tagliafico, e não toca bem piano). Em Paris, ela mora em um pequeno apartamento na Rue la Pérouse, próximo ao Arco do Triunfo, cujo interior é todo decorado com motivos orientais (chineses, japoneses) e cores exóticas (zebrado, púrpura). Profissionalmente, ela recebe aí homens de origens sociais distintas, bem como algumas mulheres, todos sempre desacompanhados. É justamente esta cocotte a responsável por convidar o herói a um salão muito diferente dos que ele costuma freqüentar, o dos Verdurin.

Mas em que consiste a distância entre Swann e os Verdurin? Ora, ela é, a princípio, social, mas envolve também visões de mundo e modos de vida diferentes. Swann - o judeu das altas finanças, das companhias mundanas bem cotadas e das amantes desqualificadas - vê-se agora em um ambiente pequeno-burguês, tão democrático quanto dogmático. Nele, os Verdurin, oriundos de uma rica e obscura família provincial, acolhem o Dr. Cottard e sua esposa, um pianista anônimo e sua tia, M. Saniette (um arquivista abastado) e a própria Odette. Eis aí o mainstream do salão.

Chama atenção o fato de o narrador descrever tal grupo como uma seita religiosa. Assim, para se fazer parte dela, bastava o pretendente aderir a certos credos, dentre os quais se destacam a fé nas habilidades médicas do Dr. Cottard e na perícia do pianista. Não obstante, a exclusividade de culto é exigida. Uma vez dentro, o fiel tem de criticar todos os que não estivessem ali, sobretudo a alta sociedade, afirmando a superioridade do salão. Daí provém, por exemplo, o veto de Mme. Verdurin à presença de mulheres, pois seriam elas mais afeitas a intrigas que os homens e pouco dadas à devoção - exceto aquelas que, por suas ocupações, ajudassem a reunir os fiéis, como a tia do músico e Odette. Daí provém também o processo de seleção de novos membros, sempre por indicação, bem como os testes aos quais eles são constantemente submetidos, a saber, os eventos nos quais devem rezar a cartilha do grupo.

Ora, toda a tensão da primeira parte de Un Amour de Swann está no fato de, uma vez dentro da seita, Swann resistir à adesão total. Por um lado, ele não só se recusa a maldizer o "mundo exterior”, como não deixa de freqüentar este mundo (seja ele o dos salões mundanos, seja ele o da aman- 
te operária). Por outro lado, ele se apaixona perdidamente, e eu diria mais, esteticamente, por Odette. Para o grupo, e sobretudo para Mme. Verdurin, a cortesã é um instrumento de coesão, jamais alvo de afetos desinteressados. Mas para Swann, ela, que não é exatamente bela, torna-se sedutora demais por seus contornos nebulosos, típicos de um ser marginal (dentre os quais destaco aqui sua profissão e sua orientação sexual ambivalente).

A tensão oriunda deste (não)pertencimento de Swann atinge o paroxismo de sua resolução tão logo novos membros aderem à seita. Dentre eles estão Brichot, o professor da Sorbonne mundialmente conhecido (embora cético quanto à sua profissão), assim como o Conde de Forcheville, um exilado dos salões nobres convidado, como Swann, por Odette. Forcheville, sobretudo ele, revela-se o mundano convertido exemplar, disposto a assumir os credos da seita e a renegar seu passado. Ele é, de certo modo, o oposto de Swann, com o agravante de ser ainda um dos concorrentes quanto ao amor de Odette. Depois de provocar o ostracismo de Saniette, o arquivista amigo dos anfitriões, a força de Forcheville fica clara. Não demora muito e Swann se torna o alvo dele e de boa parte do grupo. O herói logo passa a não mais ser chamado aos soirées da seita, o que o deixa angustiado justamente por não poder mais estar naquele tempo/espaço com Odette.

Na seqüência de UnAmour de Swann, já impedido de ir aos Verdurin, Swann aparece no salão mundano dos Saint-Euverte, do tipo que jamais deixou de freqüentar. Certas diferenças com relação ao ambiente anterior se fazem notar, dentre as quais sublinho a considerável presença de mulheres e a hierarquia não só da estrutura do salão, mas da relação mantida entre ele e os outros salões. Há entre os convivas, por exemplo, damas pouco prestigiadas, como a tímida Mme. Cambremer ou a inconveniente Mme. de Gallardon. Mas há também aí Mme. de Laumes, descendente dos Guermantes, íntima de Swann e a mais ilustre convidada. Por fim, convivem figuras como a própria anfitriã (Mme. de Saint-Euverte), o general Froberville e o Marquês de Bréaute, burgueses ou nobres de renome relativo, além, por certo, dos artistas e dos empregados a quem cabe todos entreter. Outro dado importante é o lugar de relativo prestígio ocupado por este salão: a despeito de convidadas de menor renome, participam deles alguns íntimos dos Guermantes (o salão que, no início do romance, ocupa o pólo mais alto da hierarquia mundana), algo impensável para salões menores. O dado interessante nesse trecho é que, durante o tempo de sua permanência na reunião, 
Swann não deixa de pensar em Odette um só instante, desprezando a todos os incapazes de compreender seu amor. E é bom sublinhar que este amor é capaz mesmo de comprometer suas relações: afinal, manter um vínculo estável com uma cocotte pode não ser um tabu, mas está longe de representar uma ascensão social.

Um dos traços distintivos das ações de Swann é, portanto, a busca por autonomia diante das determinações sociais. Ele almeja, ao mesmo tempo, estar e não estar no círculo dos Verdurin; estar e não estar na altasociedade, seja ela a dos Saint-Euverte ou a do superior salão de Mme. de Guermantes. Outro indício disto é justamente seu amor por Odette, algo que só faz sentido justamente na medida em que ela é um ponto de encontro no qual se (con)fundem todos os universos sociais possíveis (veja-se o Gráfico 1). Dentre os demais personagens, na seqüência do romance, o narrador apresenta similar padrão comportamental, assim como toda uma gama de importantes heróis próximos a ele (Bloch, Bergotte, Robert de Saint-Louptodos conectados a, ou iniciados por, Swann e Odette). Nesse sentido, Proust rompe com um herói típico de Balzac, como Eugéne de Rastignac, que não quer viver esteticamente, mas apenas ascender na sociedade. Ele segue, aí sim, o Flaubert de L'Éducation Sentimental, cujo protagonista, Frédéric Moreau, se recusa a escolher, conservando-se por algum tempo num estado de indefinição social.

A comparação com Frédéric traz ainda à tona outro traço de Swann, mas este por oposição. Ao contrário do herói de Flaubert, desejoso de construir um espaço de vivência estética na negação das possibilidades sociais (um manter-se eternamente jovem, como notou Bourdieu), aqui há uma positividade. Pode-se notar o conteúdo do amor de Swann por Odette a partir de um único episódio: ao escutar, no salão dos Verdurin e no dos Saint-Euverte, a mesma frase da Sonata para piano e violino de M. Vinteuil, Swann é transportado para um tempo sem tempo, no qual ele experimenta seu amor sensivelmente, em meio à recordação dos momentos felizes que teve com Odette $^{11}$. A partir daí, pode-se concluir que a vivência da arte não

11 Para precisar a centralidade do rememorar no romance, veja-se um escrito crítico do próprio Proust. In: PROUST, Marcel. Essais et articles. Paris: Gallimard, 1994, p. 255-60. 
está nos artistas dos salões, nem nos nobres, nem nos burgueses, mas em seres solitários comprometidos com um não-comprometimento, algo complementado e realçado por seus exames memoriais involuntários. É isto o que, de outro modo, afirma o próprio Proust no inacabado Contre SainteBeuve:

Na realidade, aquilo que se dá ao público é aquilo que se escreve só, por si mesmo, é bem a obra de si mesmo... Aquilo que ocorre entre íntimos [...] é obra de um eu bem mais exterior, não do eu profundo que somente se reencontra fazendo abstração dos outros e do eu que conhece os outros, o eu que esperava enquanto se estava com os outros, que bem entende o único real, e pelo qual só os artistas acabam de viver, como um deus que vão deixando aos poucos e a quem sacrificaram uma vida que só serviu para honrá-lo ${ }^{12}$.

\section{Os usos sociais dos clássicos em Proust}

Discutida a estética proustiana, resta delinear o espaço dos clássicos greco-latinos nela, seja como eventual cânone evocado a partir destas referências, seja como mero conjunto de dados mobilizado no enredo de suas obras. Com relação a este ponto, Proust permite recuperar e discutir o caráter excludente da sociedade (e, por extensão, do ensino) de sua época. De fato, os antigos aparecem no romance como uma espécie de bem simbólico distribuído de forma desigual: todos têm acesso a eles, mas utilizam-nos de modos e com freqüências diferentes. Tais referências são incomuns, por exemplo, entre figuras subalternas ou pouco ilustradas, como os empregados e os pequeno-burgueses. Assim, o escultor que restaura a igreja de Combray fala, constrangido, de Aristóteles e Virgílio como se fossem velhos

12 Cf. Id. Contre Sainte-Beuve. São Paulo: Iluminuras, 1988, p. 54. 
conhecidos seus. De pronto o narrador sugere uma origem humilde ao homem, pois, como Françoise, a empregada da família, ele não consegue perceber a distância (temporal, mas também social) que o separa destas ilustres figuras. Uma das tias provincianas do narrador também merece aqui menção: se fosse mais culta e aberta ao mundo, diz ele, compreenderia o claro paralelo entre sua biografia e o mito de Aristeu ${ }^{13}$.

Mas tais (não) usos dos clássicos são só algumas das formas de exclusão. A elite letrada do romance também se vale deles para marcar positivamente o seu e o lugar dos outros. Assim, por exemplo, o narrador explica o espaço ao mesmo tempo íntimo e subalterno de Françoise em sua família valendo-se da imagem da criada de uma tragédia grega; já Brichot, o professor da Sorbonne antes mencionado, não sem ambigüidade, refere-se ao salão dos Verdurin como uma república ateniense; e ainda Swann, quando sai atrás de Odette na noite de Paris, não deixa de comparar sua busca à de Orfeu $^{14}$. Em todo caso, o importante aqui é perceber que estes informes de cultura não diferem em essência de outros dados eruditos: o narrador também localiza socialmente Françoise por seu modo de pronunciar uma expressão erudita à época, como “raio-x”, ou mesmo compara a percepção da sociedade por suas tias ao sistema de castas na Índia ${ }^{15}$. São todos dados eruditos, marcadores de distância social, os quais podem ser mobilizados com maior ou menor maestria, dependendo da inteligência e dos anos de estudo acumulados de quem os utiliza. Neste sentido, não é possível dizer se Proust é contra ou a favor das reformas do ensino. Em todo caso, ele permite entrever que, independente do lado, as informações continuarão a serviço da reprodução social de uma certa elite (seja ela a científica da nova república - representada por Brichot e Legrandin -; seja ela a herdeira do humanismo do Antigo Regime; seja ela, por que não, a dos artistas de vanguarda à la Proust).

Há, portanto, um claro padrão no uso dos clássicos no enredo do romance, uma vez que pode ser constatada uma homologia entre sua utiliza-

13 Para os dois exemplos, id. À la Recherche du Temps Perdu. Op. cit., respectivamente p.

126 e 24.

14 Ibid., p. 51, 79 e 206.

15 Ibid., p. 51 e 22-3. 
ção por personagens os mais diversos e os lugares a partir dos quais cada um deles se pronuncia. E isto vale inclusive para os próprios heróis do romance, os quais buscam justamente escapar das determinações sociais. Não deixa de ser interessante observar como, dentre eles, os que mais se valem dos antigos para falar sobre o mundo sejam os que, a princípio, não deveriam ter relações íntimas com tal temática: o narrador, Swann e Bloch. No caso do narrador, isso ocorre porque, oriundo da pequena-burguesia provincial, ele deveria ser tão ignorante dos antigos quanto seus familiares. E o mesmo aparente paradoxo vale ainda para Swann e Bloch, os dois principais personagens judeus no romance. Bloch, por exemplo, a despeito de seus parentes serem muito apegados às tradições judaicas, é virtualmente quem mais se vale de referências às culturas grega e latina ${ }^{16}$. Um caso diferente, mas igualmente revelador, é o de Robert de Saint-Loup, uma espécie de herói-exceção capaz de comprovar a regra. Com efeito, mesmo sendo um dos principais aristocratas do romance, formado em meio à melhor educação clássica e militar, ele tem como seus autores preferidos os pouco convencionais Nietzsche e Proudhon, e não os antigos, os quais certamente estudou $^{17}$.

A compreensão de um tal padrão é fundamental para se entender o papel dos cânones greco-latinos no fazer-artístico proustiano. E aqui a resposta é inequívoca: nenhum. Nada mais natural; afinal; para Proust, a arte depende de uma vivência estética memorial que, se não completamente alheia às conformações sociais, ao menos é orientada para sua transcendência rumo a um eu-individual-profundo. Em Contre-Sainte Beuve, isto é dito da seguinte forma:

Na arte não há iniciador ou precursor. Tudo está no indivíduo, cada indivíduo recomeça, por sua conta, a tentativa artística ou literária; e as obras dos predecessores não constituem, como

16 Ibid., p. 79-80 (Bloch refere-se às palavras de Bergotte como as de um oráculo délfico), 589 (Bloch presta juramento em nome de Zeus), 590 (Bloch cola a imagem de Saint-Loup à de Ares), 608 (referência a Homero para caracterizar o humor de Bloch), 610 (Bloch faz piadas sobre Catulo), 612 (Bloch diz que um de seus tios, mentiroso, poderia ser comparado a Odisseu), 706 (Bloch recita poema de temática e métrica gregas).

17 Ibid., p. 579. 
na ciência, uma verdade adquirida, da qual aproveita-se aquele que vem em seguida. Um escritor de talento hoje tem tudo por fazer. Ele não está mais avançado que Homero ${ }^{18}$.

Eis aí a expressão máxima de autonomia do artista. A arte não é como a ciência, não tem nem tradição, nem responde a demandas coletivas. Ela diz respeito, isso sim, à vida e à realização de indivíduos. Se os clássicos têm algum lugar nesta vida, eles são instrumentos de criação; do contrário, não são nada. Trata-se, enfim, de uma escrita de vanguarda, definida se não em oposição aos cânones clássicos, ao menos independe deles.

Como procurei apontar nas páginas anteriores, os clássicos aparecem na obra de Proust ou nas lembranças de um passado individual dos personagens, ou no trato com seus contemporâneos (para enquadrar a si mesmo e a eles socialmente). Os clássicos são, em suma, impensáveis em si mesmos. Tal postura, por um lado, permite tecer paralelos entre a produção literária proustiana e as reformas do sistema de ensino, tendo em vista que Grécia e Roma passam a ocupar em ambas um espaço secundário. Por outro lado, no entanto, Proust também nos convida a um exercício reflexivo. Afinal, nós, que fazemos História Antiga a partir de um país como o Brasil, talvez pudéssemos apreender com (e contra) o escritor francês a enfrentarmos aspectos de nossa profissão sobre os quais muitas vezes silenciamos e que vão além dos objetos por nós tratados. Afinal, a que interesses nosso trabalho de erudição atende? A quem e como ele segrega? Quem sabe também não possamos tratar os clássicos a contrapelo, refutando ontologias e aceitando com consciência a responsabilidade de tratar destes temas em um país tão repleto de desigualdades. 
GRÁFICO I: O mundo dos salões parislenses ética e estética em Un Amour d e Swann

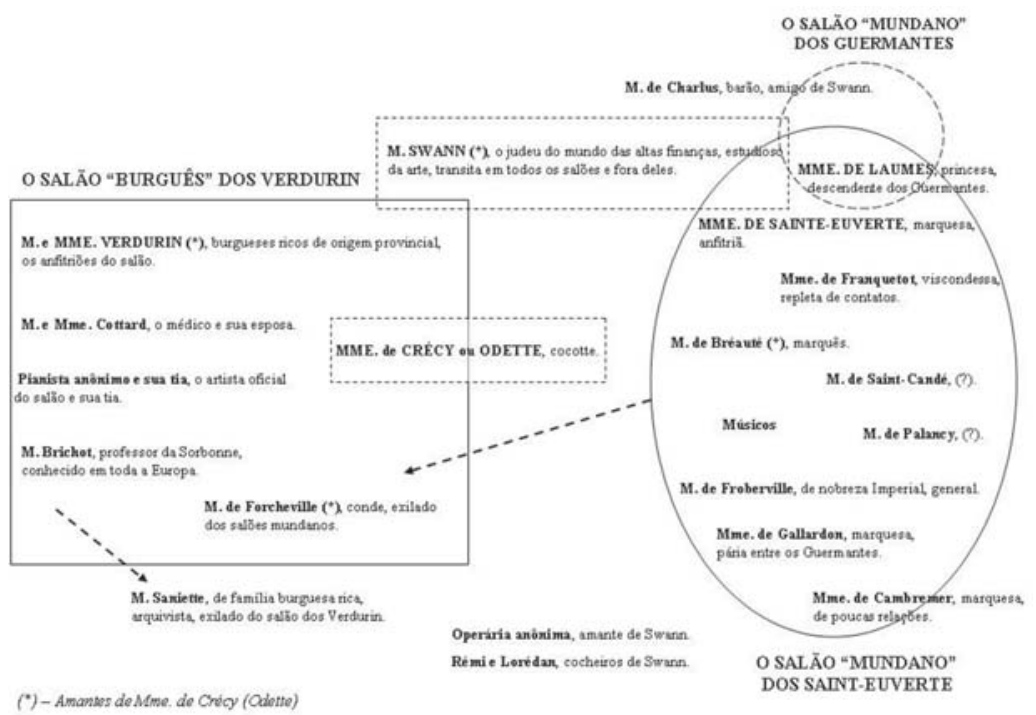

